\title{
Significance of epidermal growth factor receptor gene mutations in squamous cell lung carcinoma
}

\author{
YOHEI MIYAMAE ${ }^{1}$, KIMIHIRO SHIMIZU ${ }^{1}$, JUNKO HIRATO ${ }^{2}$, TAKUYA ARAKI ${ }^{3}$, KAZUMI TANAKA ${ }^{1}$, \\ HIROOMI OGAWA ${ }^{1}$, SEIICHI KAKEGAWA ${ }^{1}$, MASAYUKI SUGANO ${ }^{1}$, TETSUHIRO NAKANO ${ }^{1}$, \\ YASUMASA MITANI ${ }^{4}$, KYOICHI KAIRA ${ }^{5}$ and IZUMI TAKEYOSHI ${ }^{1}$ \\ Departments of ${ }^{1}$ Thoracic and Visceral Organ Surgery, ${ }^{3}$ Clinical Pharmacology, and ${ }^{5}$ Medicine and \\ Molecular Science, Gunma University Graduate School of Medicine, 3-39-22 Showa-machi, Maebashi 371-8511; \\ ${ }^{2}$ Department of Pathology, Gunma University Hospital, 3-39-15 Showa- machi Maebashi, Gunma 371-8511; \\ ${ }^{4}$ K.K. DNAFORM, 75-1, Ono-cho, Tsurumi-ku, Yokohama, Kanagawa 230-0046, Japan
}

Received October 11, 2010; Accepted December 22, 2010

DOI: $10.3892 /$ or.2011.1182

\begin{abstract}
Epidermal growth factor receptor (EGFR) gene mutations have been reported to be clinically significant in non-small cell lung cancer (NSCLC). However, because most previous studies focused only on adenocarcinomas, $E G F R$ mutations in other histotypes are poorly investigated. We evaluated the frequency of EGFR gene mutations in squamous cell carcinoma (SCC) and its clinicopathological features. In total, 89 frozen tumor specimens that had been first diagnosed as SCCs, were examined for EGFR mutations in exons 19 and 21 using direct sequencing, PNA-enriched sequencing and SmartAmp2. Additionally, pathological investigation, including immunostaining for p63 and TTF-1, alcian blue staining and EGFR mutation-specific immunohistochemistry in mutation-positive samples was also performed. The frequency of EGFR mutations was 5.6\% (5/89); all mutations were deletions in EGFR exon 19. Immunohistological investigation of these samples revealed that two of five were positive for p63 and TTF-1 staining, and showed production of mucin, as evidenced by alcian blue staining. Consequently, three of the samples were considered to be true SCC at final pathological diagnosis, while the remaining two samples were revised to adenosquamous carcinoma and adenocarcinoma. The final frequency of the EGFR mutations in true SCC was $3.4 \%$ (3/87). In conclusion, EGFR mutations
\end{abstract}

Correspondence to: Dr Kimihiro Shimizu, Department of Thoracic and Visceral Organ Surgery, Gunma University Graduate School of Medicine, 3-39-22 Showa-machi, Maebashi 371-8511, Japan

E-mail: kmshimizu@gmail.com

Abbreviations: NSCLC, non-small cell lung cancer; SM, smoker; NS, non-smoker; MD, moderately differentiated; PD, poorly differentiated; wt, wild-type; mut, mutant

Key words: EGFR mutation, squamous cell carcinoma, non-small cell lung cancer, SmartAmp2 were found in a small, but significant, number of SCC tumor samples and thus EGFR mutational analysis was useful in the accurate diagnosis of SCC. Our data demonstrate that EGFR mutational analysis should be performed not only in adenocarcinoma, but also in SCC to allow accurate diagnosis and treatment.

\section{Introduction}

Lung cancer is the most common cause of cancer mortality in men, the second most common cause in women, and is responsible for 1.18 million deaths annually (1). Treatment, involving a combination of surgery, chemotherapy and radiation therapy, is determined based on histological data obtained from either biopsy or surgical specimens. Despite the greater availability of treatment and substantial research efforts, the prognosis for lung cancer remains poor. Thus, there is a continuing need for the development of more effective diagnostics and therapies.

Many studies have demonstrated that the mutational analysis of the epidermal growth factor receptor $(E G F R)$ can aid physicians in deciding the course of chemotherapy in patients with NSCLC $(2,3)$. It has been reported that NSCLC patients with a mutation in the EGFR tyrosine kinase domain, respond to tyrosine kinase inhibitors (TKIs), such as gefitinib and erlotinib (4). Most reports concerning EGFR mutations have primarily focused on adenocarcinoma, while few studies have evaluated the frequency of EGFR mutations in nonadeno NSCLC, such as squamous cell carcinoma (SCC). In these studies, EGFR mutations in SCC were observed in $0-3 \%$ of cases (5-10). However, these mutational analyses were performed by direct sequencing, which has a detection limit of approximately $20 \%$ (low sensitivity) for the target mutant allelle $(8,11)$ and a detailed pathological study of mutation-positive samples was poorly described (5-13).

Small-cell lung cancers (SCLC), for example, rarely display EGFR mutations (11), while specific combined subtypes of SCLC (such as those with adenocarcinoma) have been reported to harbor EGFR mutations (14). Likewise, though the frequency of EGFR mutations in SCC is thought to be 


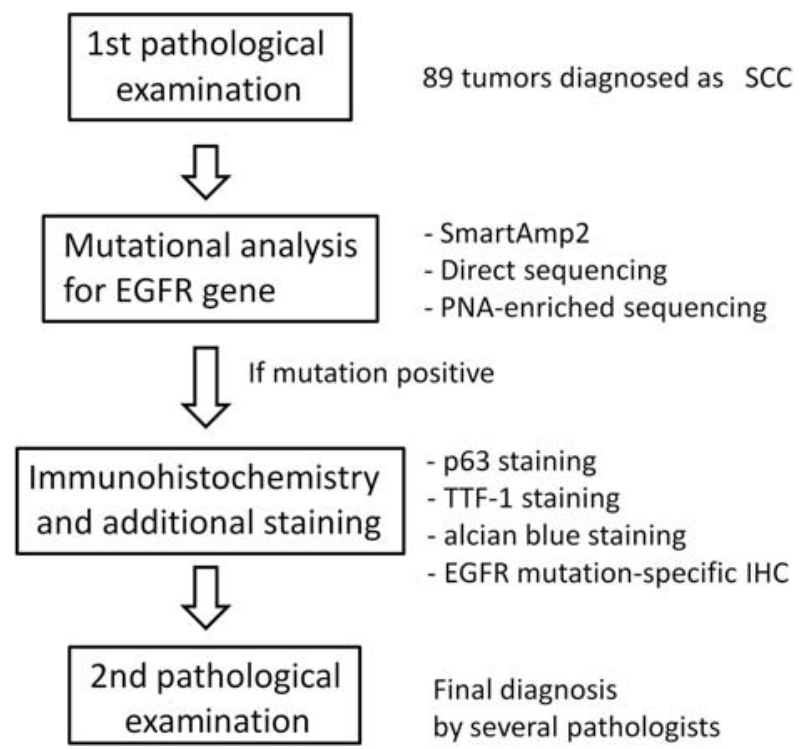

Figure 1. Schematic diagram of the study protocol.

very low (5-10), it may be possible to describe specific pathological features of SCC in EGFR mutation-positive samples. In the current study, thus, we sought to reveal the precise frequency of EGFR mutations in SCC using the highly sensitive Smart Amplification Process version 2 (SmartAmp2) combined with other conventional PCR-related methods for mutational analyses (15). Additionally, we aimed to examine the pathological features of EGFR mutation-positive samples in SCC. Here, we demonstrate the significance of EGFR mutational analysis for SCC, as well as for adenocarcinoma.

\section{Materials and methods}

Study samples and DNA extraction. The study design is depicted in Fig. 1. Tumor specimens were obtained from 89 consecutive SCC patients surgically treated at the Gunma University Hospital (Gunma, Japan) between 2003 and 2009. Institutional approval and informed consent from all patients were obtained. Specimens were classified by two experienced pulmonary pathologists according to the WHO classification system for lung carcinoma. Each pathologist classified the tumor specimens independently and unanimous agreement was obtained. Following surgical removal, a portion of each sample was immediately frozen and stored at $-80^{\circ} \mathrm{C}$ prior to DNA extraction. To suppress tumor heterogeneity and obtain a sufficient number of tumor cells, thin sections sliced from the frozen tumor surface (with maximum diameter) were selected and cut into small pieces. DNA was extracted from a 3-5-mm cube using a DNA mini kit (Qiagen, Hilden, Germany) and serially diluted to a concentration of $20 \mathrm{ng} / \mu 1$.

SmartAmp2 assay. The SmartAmp2 method is the first onestep mutation detection technology in which the amplification of the target DNA is itself, the signal of the target mutation. Using a new DNA polymerase (Aac pol) and a unique primer design we carried out SmartAmp2 assays using an EGFR mutation detection kit (K.K. DNAFORM, Kanagawa, Japan)
Table I. Patient characteristics $(\mathrm{n}=89)$.

\begin{tabular}{lcc}
\hline & No. of patients & $\%$ \\
\hline Age & & \\
Median \pm SD & $71.2 \pm 7.4$ & \\
Range & $50-86$ & \\
Gender & & 93.3 \\
Male & 83 & 6.7 \\
Female & 6 & \\
Smoking status & & 2.2 \\
Non-smoker & 2 & 97.8 \\
Smoker & 87 & \\
Pathological TNM stage & & 61.8 \\
I & 55 & 18.0 \\
II & 16 & 19.1 \\
III & 17 & 76.4 \\
IV & 1 & 23.6 \\
Pathological differentiation & & \\
Well-moderately & 68 & \\
Poorly & 21 & \\
\hline
\end{tabular}

according to the manufacturer's instructions. SmartAmp2 assays can detect deletions in the EGFR exon 19, and a mutation (L858R) in the EGFR exon 21. Although various deletions have been reported in the EGFR exon 19, PNAclamp methods allow the detection of almost all types of known deletions in a single assay $(16,17)$. The assay principles of SmartAmp2, including PNA-clamp methods, have been described previously (18). SmartAmp2 assay reactions were assembled on ice and incubated at $60^{\circ} \mathrm{C}$ for $40 \mathrm{~min}$. The Mx3000P system (Stratagene, La Jolla, CA, USA) was used to maintain isothermal conditions and monitor the transition of fluorescent intensity of intercalating SYBR-Green I (Invitrogen, Tokyo, Japan) during the reaction. We evaluated the results of SmartAmp2 assays according to the criteria of amplification versus non-amplification within $40 \mathrm{~min}$. To avoid negative errors, a positive detection was recorded when both wild-type allele amplification (control) and mutant allele amplification were observed. Each DNA sample was analyzed in duplicate.

Mutant-enriched assay for EGFR exon 19 (PNA-enriched sequencing). We detected EGFR exon 19 deletions by PNAenriched sequencing. The sequences of the primers and PNAs for PCR amplification were as follows: 5'-ACCAT CTCACAATTGCCAGTTAAC-3' (Ex19-F), 5'-CCAGATC ACTGGGCAGCATGTGGCACC-3' (Ex19-R), and N'-GAA TTAAGAGAAGCAACA-C' (PNA) $(19,20)$. PNA-enriched PCR was performed in a total volume of $25 \mu 1$ containing $1 \mathrm{X}$ PCR Gold Buffer, $1.5 \mathrm{mmol} / 1 \mathrm{MgCl}_{2}, 200 \mu \mathrm{mol} / 1 \mathrm{dNTPs}$, $500 \mathrm{nmol} / \mathrm{l}$ of each primer (Ex19-F and Ex19-R), $1 \mu \mathrm{mol} / \mathrm{l}$ PNA clamp probe, 1 unit of Taq DNA Gold Polymerase (Applied Biosystems, CA, USA), and 20 ng of genomic DNA. The PNA clamp probe was designed to be homologous to the 
Table II. Clinicopathological profile of patients with EGFR mutations.

\begin{tabular}{|c|c|c|c|c|c|c|c|c|c|c|c|c|}
\hline \multirow[b]{2}{*}{$\begin{array}{l}\text { Case } \\
\text { no. }\end{array}$} & \multirow[b]{2}{*}{ Age } & \multirow[b]{2}{*}{ Gender } & \multirow[b]{2}{*}{$\begin{array}{c}\text { Smoking } \\
\text { history }\end{array}$} & \multirow[b]{2}{*}{$\begin{array}{l}\text { First patho- } \\
\text { logical diagnosis }\end{array}$} & \multicolumn{3}{|c|}{ Mutational analysis } & \multicolumn{3}{|c|}{ IHC } & \multirow[b]{2}{*}{$\begin{array}{l}\text { Pathological } \\
\text { TMN stage }\end{array}$} & \multirow[b]{2}{*}{$\begin{array}{c}\text { Final pathological } \\
\text { diagnosis }\end{array}$} \\
\hline & & & & & $\begin{array}{c}\text { SmartAmp2 } \\
(E G F R \text { exon19) }\end{array}$ & $\begin{array}{c}\text { Direct } \\
\text { sequencing }\end{array}$ & $\begin{array}{l}\text { PNA-enriched } \\
\text { sequencing }\end{array}$ & $\mathrm{p} 63$ & TTF-1 & $\begin{array}{l}\text { Exon19 } \\
\text { mutation }\end{array}$ & & \\
\hline 1 & 67 & M & SM & MD SCC & L747-S752 del & wt & mut & + & - & - & IB & Same \\
\hline 2 & 80 & M & SM & PD SCC & $\begin{array}{c}\text { L747-E749 del, } \\
\text { A750P }\end{array}$ & wt & mut & + & - & - & IIA & Same \\
\hline 3 & 50 & M & SM & MD SCC & $\begin{array}{c}\text { L747-E749 del, } \\
\text { A750P }\end{array}$ & mut & mut & + & - & - & IV & Same \\
\hline 4 & 69 & M & SM & PD SCC & L746-A750 del & mut & mut & + & + & + & IIB & $\begin{array}{c}\text { Adenosquamous } \\
\text { carcinoma }\end{array}$ \\
\hline 5 & 57 & F & NS & PD SCC & L746-A750 del & mut & mut & + & + & + & IIIA & $\begin{array}{c}\text { Adenocarcinoma } \\
\text { with squamous } \\
\text { differentiation }\end{array}$ \\
\hline
\end{tabular}

SM, smoker; NS, non-smoker; MD, moderately differentiated; PD, poorly differentiated; wt, wild-type; mut, mutant.

wild-type allele. Thermal cycling conditions included a preincubation step at $94^{\circ} \mathrm{C}$ for $5 \mathrm{~min}$, followed by 40 cycles at $94^{\circ} \mathrm{C}$ for $15 \mathrm{sec}, 60^{\circ} \mathrm{C}$ for $30 \mathrm{sec}, 72^{\circ} \mathrm{C}$ for $1 \mathrm{~min}$, and a final extension at $72^{\circ} \mathrm{C}$ for $5 \mathrm{~min}$. PCR products were purified using the QIAquick PCR purification kit (Qiagen). DNA sequencing was performed with the ABI PRISM 3100 DNA Analyzer (Applied Biosystems) using the ABI PRISM BigDye Terminator version 3.1 (Applied Biosystems) with the Ex19-F primer.

PCR-based direct sequencing. We performed PCR-based sequencing of the EGFR exon 19 using the reaction conditions as described for PNA-enriched PCR. The PCR products were then purified and sequenced as described. In direct and PNAenriched sequencing, the sequence was determined as a mutant or wild-type sequence when an elevation over the level of non-specific background noise was observed.

Histochemistry, immunohistochemistry and second pathological examination. Tumor tissue specimens were fixed in $10 \%$ formaldehyde, and embedded in paraffin wax. The paraffin sections were cut at $3 \mu \mathrm{m}$, and stained with hematoxylin and eosin (H\&E) and with the alcian blue method. Immunohistochemical staining was performed on the same paraffin sections using anti-p63 mouse monoclonal antibodies (1:1, Nichirei, Tokyo, Japan) and anti-TTF-1 mouse monoclonal antibodies (1:200, Thermo Fisher Scientific, Cheshire, UK). The sections were immunostained with an automated stainer, the Ventana XT system Benchmark (Roche Diagnostics K.K., Basel, Switzerland). The streptoavidin-biotin method is provided in this system. To detect the EGFR mutant proteins via mutation-specific antibodies, EGFR exon 19 mutationspecific immunohistochemistry (IHC) was performed using the same paraffin sections as described previously $(21,22)$. Rabbit monoclonal primary antibodies with specificity for the 15-bp deletion in EGFR exon 19; EGFReceptor (E746A750del Specific) (6B6) XP ${ }^{\text {Tм }}$ Rabbit mAb (Cell Signaling
Technology, Inc., Beverly, MA) were used (1:100) and IHC was performed according to the manufacturer's recommendations. For positive samples from IHC, a section slide of the tumor was divided into several pieces (the adenocarcinomatous and squamous cell carcinomatous components) and macrodissected for DNA extraction using the QIAamp DNA FFPE tissue kit (Qiagen) as described previously (16). Mutational analyses were performed on extracted DNA samples using SmartAmp2 and PNA-enriched sequencing. Following histochemical studies and analysis of the IHC data, several pathologists reviewed the tumor specimens and a final diagnosis was agreed.

\section{Results}

Patient characteristics. The SCC patients consisted of 83 men and 6 women; their characteristics summarized in Table I. The median age of the patients was 71 years (range, 50-86 years). Most patients were heavy smokers, except for two patients, one female and one male, who were non-smokers. The pathological TNM stage according to the 6th edition of the Union Internationale Contre le Cancer (UICC) staging system was stage I in 55 patients, stage II in 16 patients, stage III in 17 patients, and stage IV in one patient.

Detection of EGFR gene mutations in clinical samples. We examined the EGFR gene mutations in 89 SCC tumor samples and compared the results of SmartAmp2, direct, and PNAenriched sequencing. The results from mutation-positive samples are summarized in Table II. Typical data obtained from the various mutational analysis methods are shown in Fig. 2. In case 1, we detected mutations in EGFR exon 19 by SmartAmp2 and PNA-enriched sequencing, but not by direct sequencing. Among the $89 \mathrm{SCC}$ tumor samples examined in this study, five $(5.6 \%)$ samples were found to possess mutations in the EGFR, as assessed by SmartAmp2 (cases 1-5). All mutations were deletions in exon 19; no mutation was 


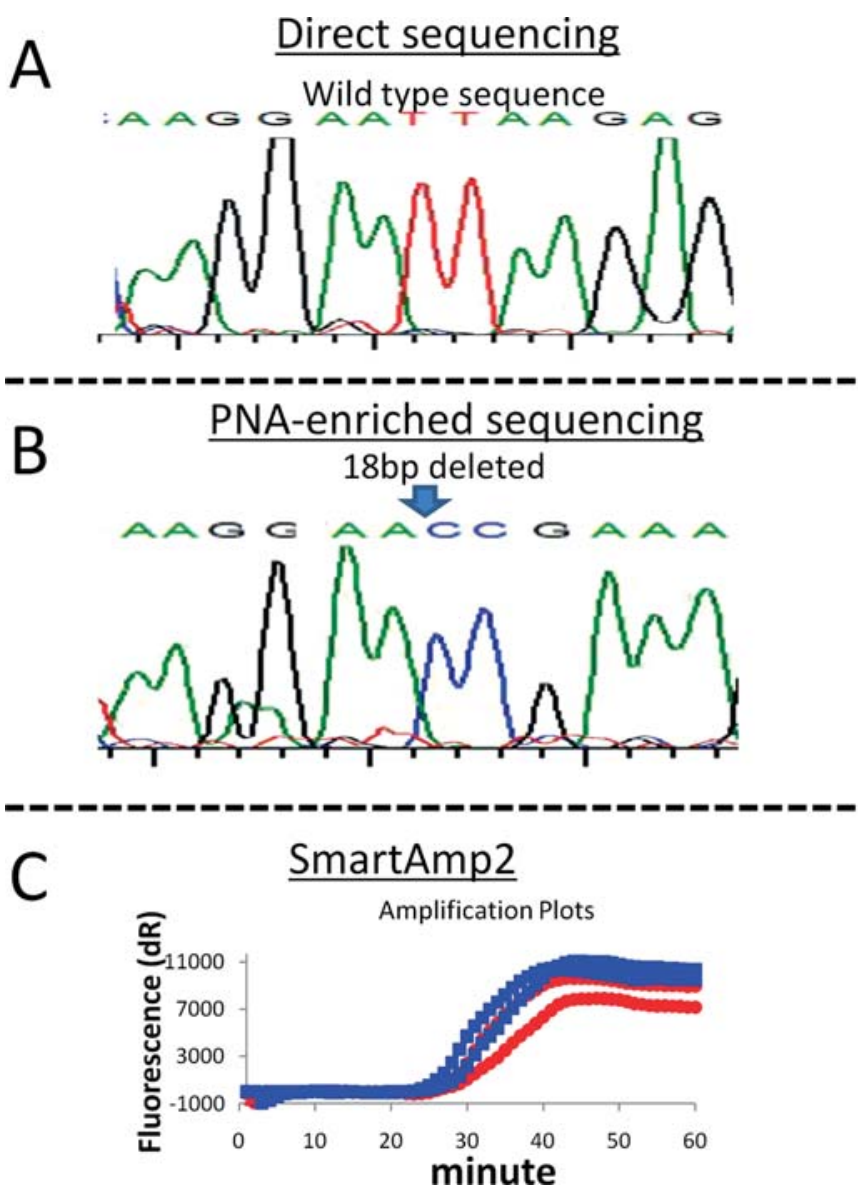

Figure 2. Typical results obtained from various methods of detection for $E G F R$ exon 19 deletions (case 1). The wild-type allele is shown by direct sequencing (A), however, the 18-bp deletion was detected by PNA-enriched sequencing (B). In SmartAmp2 assays (C), wild-type (red curve) and mutant allele (blue curve) amplification are indicated. As the amplifications began within $40 \mathrm{~min}$, it is interpreted as a mutation-positive result.

detected in exon 21. Identical data were obtained from PNAenriched sequencing; however, only three of five samples were detected by direct sequencing.

Immunohistochemistry and second pathological examination. All results are summarized in Table II. P63 staining, TTF-1 staining, and EGFR exon 19 mutation-specific IHC were performed for all samples that harbored EGFR mutations.

Cases 1-3. Cases 1-3 were positive for p63 and negative for TTF-1 staining. Case 1 is shown as an example in Fig. 3. Regarding cases 1-3, EGFR exon 19 mutation-specific IHC was performed; however, no positive sample was found. A SCC showed positive p63 staining and negative TTF-1, consistent with these cases. The cases displayed the typical morphological features of SCC (Fig. 3) and no suggestion of any other pathological type. We thus concluded that these cases were SCC at final diagnosis.

Case 4. At first pathological examination, this case was diagnosed as SCC, according to the pathological morphology of the H\&E staining (Fig. 4A and B). However, in IHC, this case was positive for both p63 and TTF-1 staining (Fig. 4C), which was atypical for SCC. We thus performed alcian blue staining and observed that areas which had been suggested as SCC tissue, were, in fact, rich in mucin production (Fig. 4D). Taking these findings into account, a second pathological examination revealed that these areas displayed an adenocarcinoma component, occupying $>10 \%$ of the tumor section. We thus concluded that this case was an adenosquamous carcinoma at a final diagnosis. In EGFR exon 19 mutationspecific IHC, all areas displayed positive staining regardless of the adenocarcinoma or squamous carcinoma component (Fig. 5). Moreover, when DNA was extracted from each area via macrodissection, each area displayed $E G F R$ mutations by SmartAmp2 and PNA-enriched sequencing (data not shown).

Case 5. Similar to case 4, this case was first diagnosed as SCC, according to the pathological morphology of the H\&E staining (Fig. 6A and B). In IHC, this case was positive for p63, TTF-1 staining (Fig. 6C), and some areas of mucin production, which had been suggested to be SCC tissue (Fig. 6D). Taking these findings into account, a second pathological examination revealed that the majority of the area was an adenocarcinoma and that the squamous carcinoma component was observed as only a small portion of the tumor. The final diagnosis was thus adenocarcinoma with squamous differentiation. In EGFR exon 19 mutation-specific IHC, all areas, including the squamous differentiated parts, were positive. As in case 4, we confirmed that each area possessed EGFR mutations via SmartAmp2 and PNA-enriched sequencing (data not shown). Based on these results, cases 4 and 5 were discounted as SCC; thus, for 87 tumor samples, typical SCC was the final pathological diagnosis. The frequency of $E G F R$ mutations in true SCC was $3.4 \%$ (3/87) by the SmartAmp2 assay and PNA-enriched sequencing, and $1.1 \%$ (1/83) by direct sequencing.

\section{Discussion}

In the current study, we sought to improve our understanding of the molecular and pathological status of SCC, which has remained unclear, compared to that of adenocarcinoma. We also aimed to reveal the true frequency of EGFR mutations in SCC. Previous reports, using low sensitivity methods, indicated that EGFR mutations were rare (5-10). Here, we used highly sensitive methods to evaluate 87 SCC tumor samples. We observed that three $(3.4 \%)$ of these tumors were identified as having EGFR mutations by SmartAmp2 (two additional samples were also identified, but they were ruled out from SCC as discussed). Despite the low frequency of EGFR mutations detected, this detection was more sensitive than direct sequencing. Thus, if SmartAmp2 had been used in previous reports, the reported frequency of mutations in SCC may have been higher.

We additionally examined features of EGFR mutationpositive samples. We hypothesized that SCC with $E G F R$ mutations may be associated with adenocarcinoma (as reported EGFR mutations are specific for adenocarcinomas). We therefore performed p63 and TTF-1 staining on EGFR mutation-positive samples as a method of differentiating SCC and adenocarcinoma, respectively $(23,24)$. As expected, cases 1-3 were positive for p63 and negative for TTF-1 

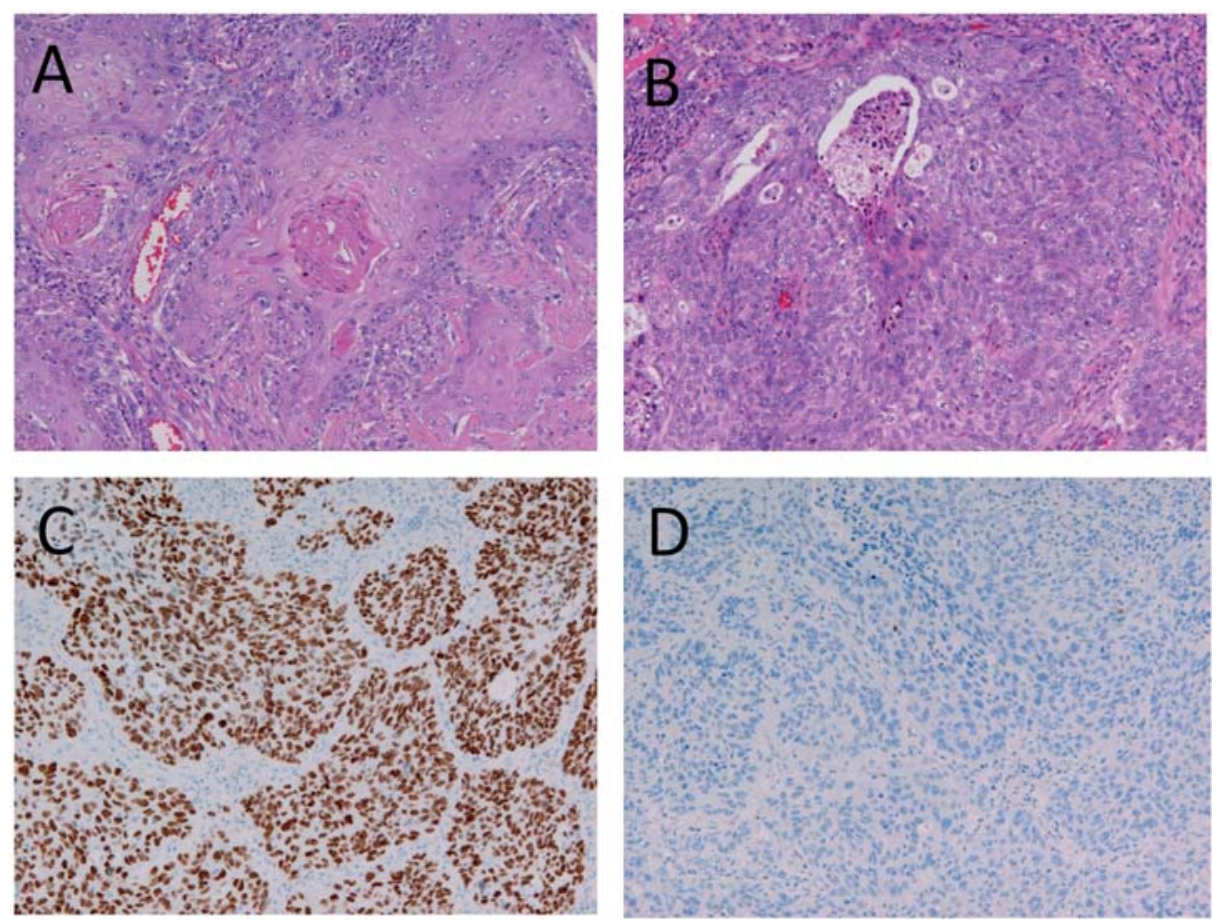

Figure 3. Typical features of squamous cell carcinoma. (A: case 1, B-D: case 3) (A) Moderately differentiated squamous cell carcinoma with keratin pearl formation (H\&E stain). (B) Moderate differentiation of squamous cell carcinoma forming a sheet-like growth pattern (H\&E stain). (C) Tumor samples positive for $\mathrm{p} 63$ staining. (D) Tumor samples negative for TTF-1 staining.
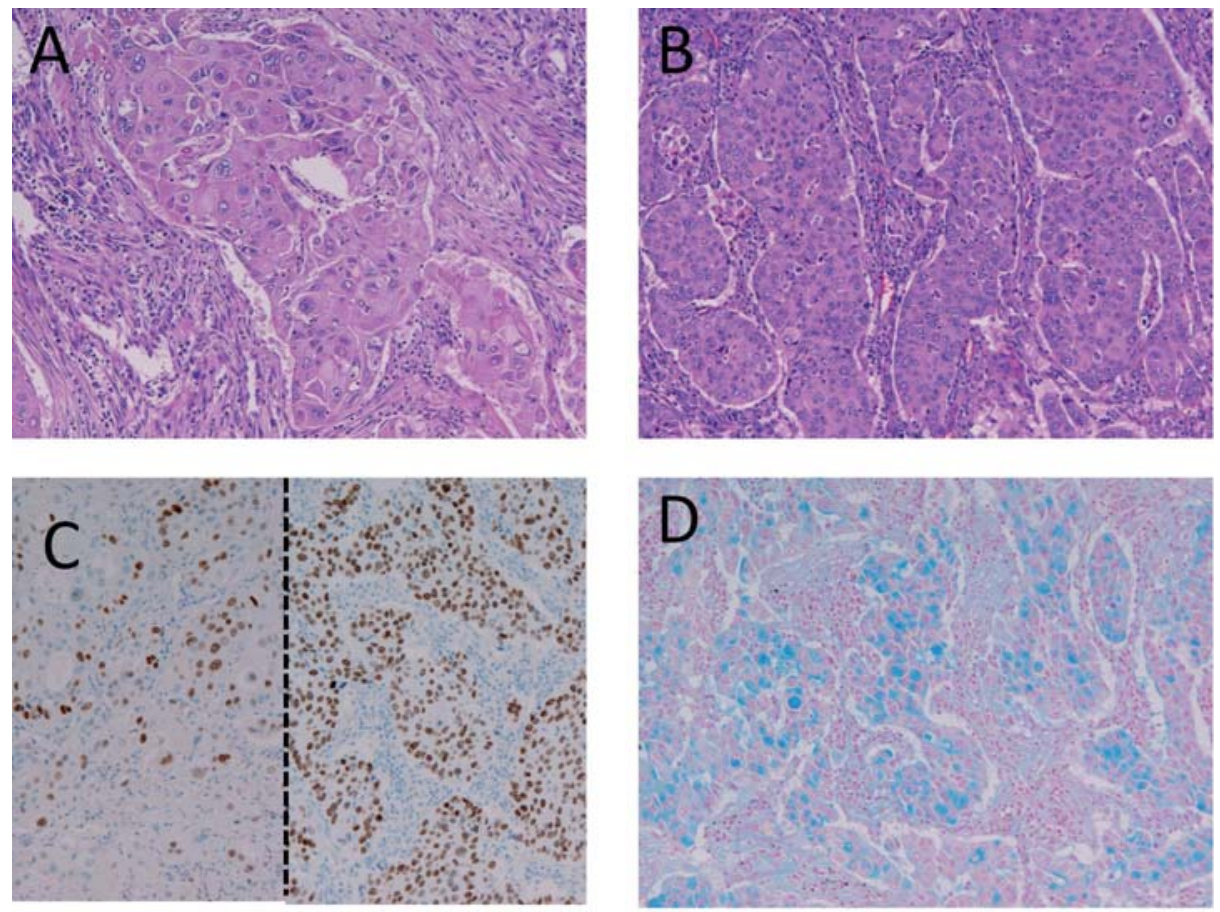

Figure 4. Adenosquamous carcinoma (case 4). (A) Squamous cell carcinoma component (H\&E stain). (B, D) Adenocarcinoma component. Although thought to be a part of the squamous cell carcinoma component, mucin production was positive by alcian blue staining and was determined to be an adenocarcinoma component, with a solid and acinar pattern. (B) H\&E staining. (C) Tumor samples positive for both p63 (left) and TTF-1 (right) staining. (D) alcian blue staining.

staining. However, cases 4 and 5 were positive for both p63 and TTF-1, and mucin production was evident via alcian blue staining. Based on the these results, our pathological diagnosis was revised to adenosquamous carcinoma in case 4 and to adenocarcinoma with squamous differentiation for case 5 , following a second pathological examination. For all the 


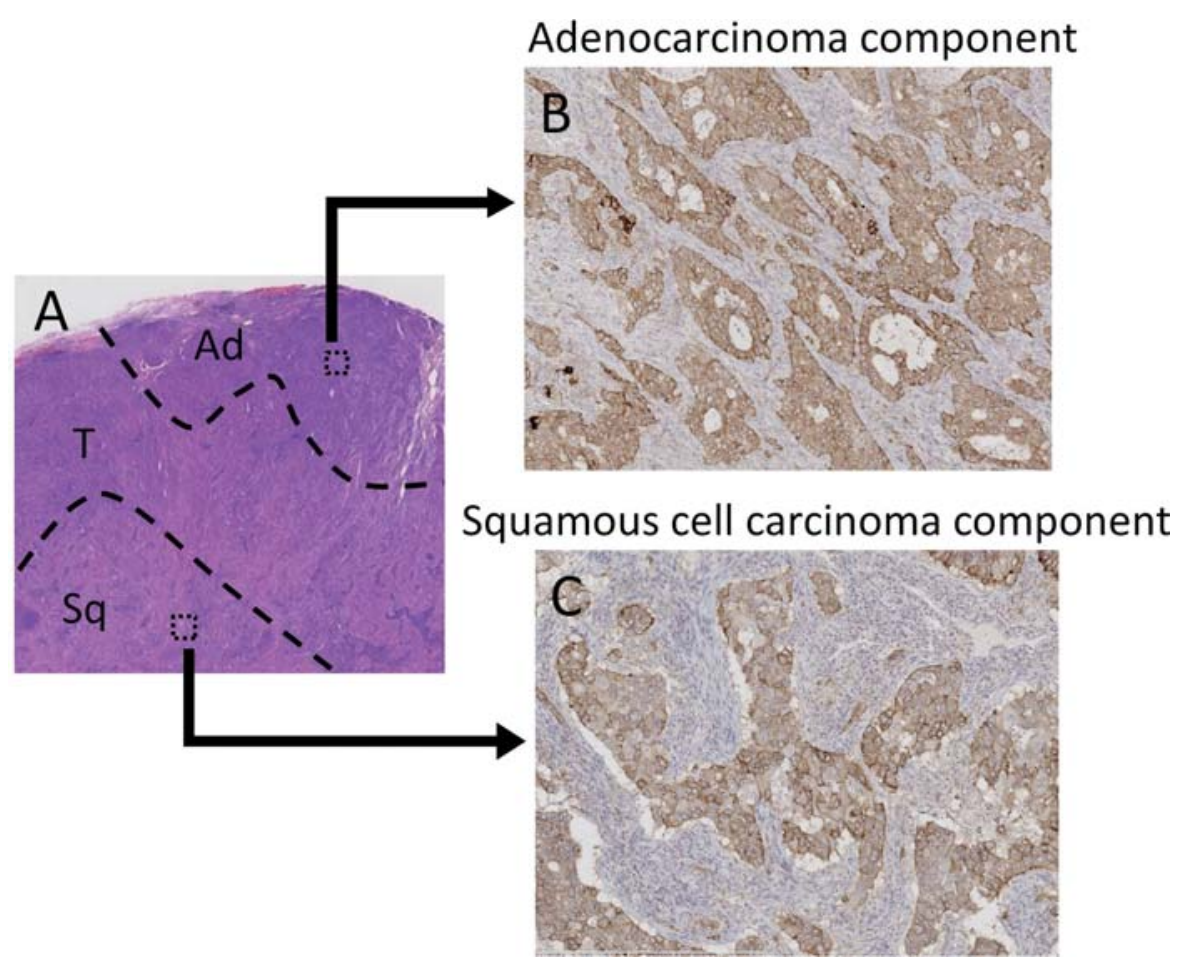

Figure 5. Adenocarcinoma and squamous cell carcinoma components. (A) Low-power field of tumor sections (case 4, H\&E). Adenocarcinoma (Ad) and squamous cell carcinoma (Sq) components found in tumor sections. Most parts were transitional areas (T) displaying a mixture of both components. (B, C) EGFR exon 19 mutation-specific IHC observed in case 4 (B) adenocarcinoma component (C) squamous cell carcinoma component. Both components were positive for staining.
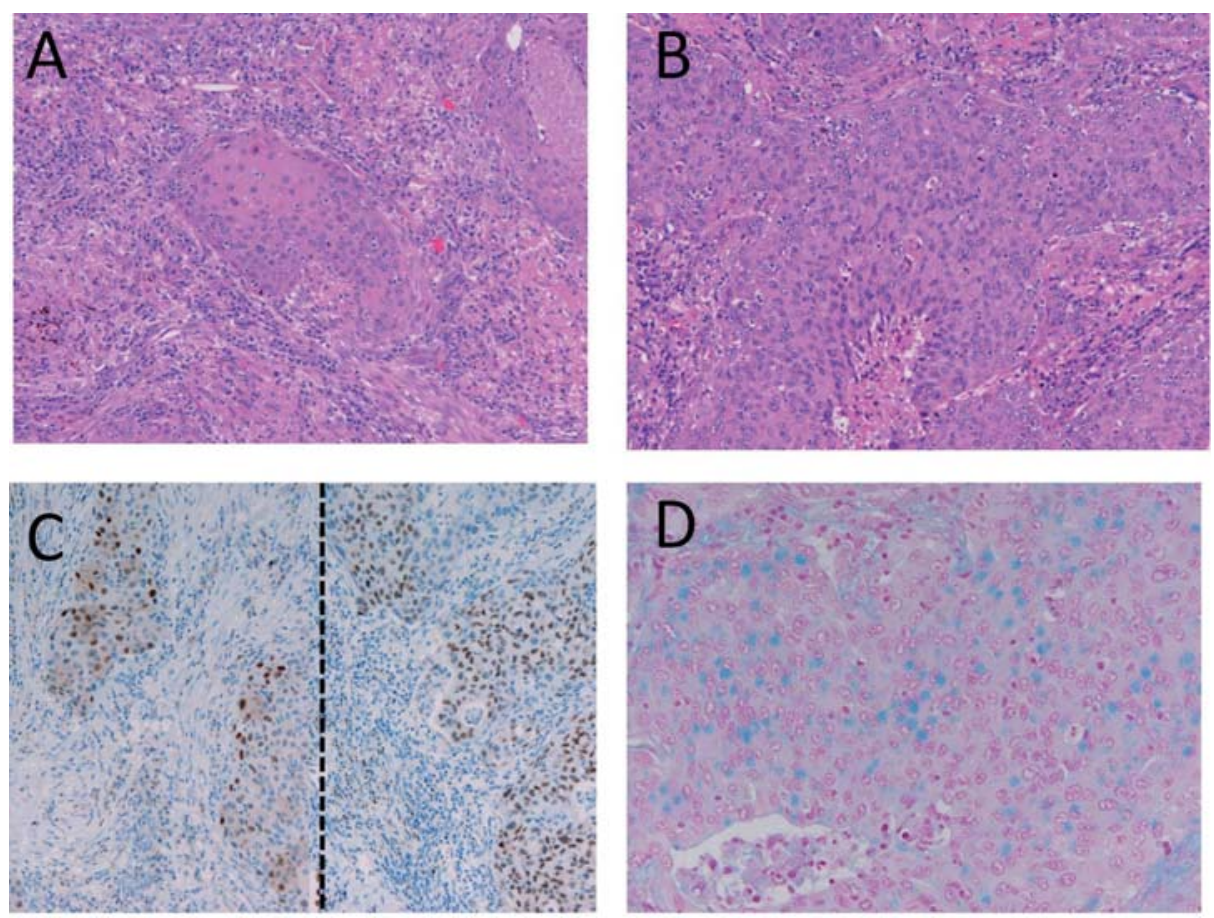

Figure 6. Adenocarcinoma with squamous differentiation (case 5). (A) Squamous cell carcinoma component (H\&E stain). (B, D) Adenocarcinoma component. Although it was thought to be a part of the squamous cell carcinoma component initially, mucin was positive by alcian blue staining and was therefore determined to be an adenocarcinoma component with a solid and acinar pattern. (B) H\&E stain. (C) Positive for both p63 (left) and TTF-1 (right) staining. (D) alcian blue staining.

EGFR mutation-positive samples (cases 1-5), EGFR exon 19 mutation-specific IHC was performed. Although cases 1-3 were negative for staining, this is consistent with previous studies indicating that this immunostaining was sensitive for 
the 15-bp deletion, but less sensitive for other deletion types in SCC (22). Cases 4 and 5, however, displayed positive staining for both the adenocarcinomatous component and the squamous cell carcinomatous component (Fig. 5). This was confirmed by SmartAmp2 and PNA-enriched sequencing from the DNA extracted from each component. In previous reports, there was great interest as to whether the heterogeneity of EGFR mutations was evident in adenosquamous cell carcinoma samples $(25,26)$. Because $E G F R$ gene mutations were believed to be specific for adenocarcinoma, it was suggested that EGFR mutations would be located only in the adenocarcinomatous components, but would be absent in the squamous cell carcinomatous component in adenosquamous carcinoma tissue. Previous reports have demonstrated that EGFR mutations were detected in DNA extracted from both tissue components $(25,26)$; however, the possibility remained that these results were artifacts, caused by the contamination of the two component cells during microdissection or extraction. In our IHC, contamination could not influence the results and thus our findings support the notion that EGFR mutations are found in both components in adenosquamous tissue. We present the first study to examine the heterogeneity of $E G F R$ mutations in adenosquamous carcinoma tissue by EGFR exon 19 mutation-specific IHC. That no heterogeneity was observed in this assay is helpful in understanding the carcinogenesis of adenosquamous carcinoma. It seems unlikely that identical EGFR mutations occurred in both adenocarcinomatous and squamous cell carcinomatous components simultaneously. Thus, we suggest a monoclonal pathway whereby each component of the adenosquamous carcinoma originated from common progenitor cells, which seems more probable than a polyclonal pathway in the histogenesis of adenosquamous carcinoma.

Currently, pathological diagnosis is of great importance because it dictates the therapeutic strategy used (27-29). For example, bevacizumab or pemetrexed are not available for SCC therapy, although bevacizumab is one of the few drugs found to significantly impact lung cancer survival $(30,31)$. Johnson et al reported that some SCC patients treated with bevacizumab experienced severe pulmonary hemorrhage. This led to the exclusion of SCC cases from bevacizumab therapeutic adoption (32). Pemetrexed is also expected to be effective in lung cancer chemotherapy; however, its use is permitted only in non-squamous NSCLC, because previous studies showed little benefit in SCC $(33,34)$. Thus, distinguishing SCC from other histological types is important when making therapeutic decisions. In this regard, EGFR mutational analysis is helpful in differentiating the diagnosis of poorly differentiated SCC. As the frequency of $E G F R$ mutations in adenocarcinoma or adenosquamous carcinoma was much higher than that of $\operatorname{SCC}(2,35-38)$, if EGFR mutation-positive samples are found in SCC, we should reconsider the pathological diagnosis. This makes the EGFR mutational analysis a unique differential diagnostic tool using the differences in mutational frequency.

It is also important to note that some SCC cases (such as cases 1-3) displayed EGFR mutations. Although TKIs, such as gefitinib, were originally indicated for the treatment of advanced or metastatic NSCLC, they have rarely been used for tumors other than adenocarcinoma, despite reports showing that TKIs may be effective for EGFR mutationpositive SCC or adenosquamous carcinoma. Mitsudomi et al reported the case of a male patient with adenosquamous carcinoma expressing EGFR mutations. The patient had a large, recurring chest-wall mass, which showed a dramatic response to gefitinib (36). Park et al reported three SCC patients with $E G F R$ mutations that were responsive to gefitinib therapy, while 17 SCC patients with wild-type $E G F R$ showed a response in only one patient (39). Although these reports are limited, the use of TKIs for lung cancers other than adenocarcinoma with EGFR mutations, might become an option for therapy as the trial numbers increase.

In clinical practice, not all cancers display a definite pathological diagnosis. For example, some samples obtained through transbronchial lung biopsy or transcutaneus needle biopsy are either too small, or have too much destruction (40-43), meaning their malignancy can barely be determined. Such samples therefore remain pathologically unclassified (so-called 'not-otherwise-specified', NOS). This is problematic for physicians because current therapeutic strategies are often selected based on the pathology. As EGFR mutations can be detected from even such small biopsy specimens, EGFR mutation-positive cancer can provide a new factor as to whether the histotype is adenocarcinoma, adenosquamous carcinoma, or SCC (44-46).

In conclusion, we demonstrate the potential use of EGFR mutational analysis in non-adeno NSCLC, including SCC. Although mutational analysis does not replace a pathological examination, it can provide valuable clues to the pathological/ clinical diagnosis and subsequent therapeutic decisions.

\section{Acknowledgements}

The present study was performed at the Department of Thoracic and Visceral Organ Surgery, Gunma University Graduate School of Medicine, Japan.

\section{References}

1. Parkin DM, Bray F, Ferlay J and Pisani P: Global cancer statistics, 2002. CA Cancer J Clin 55: 74-108, 2005.

2. Paez JG, Janne PA, Lee JC, et al: EGFR mutations in lung cancer: correlation with clinical response to gefitinib therapy. Science 304: 1497-1500, 2004.

3. Lynch TJ, Bell DW, Sordella R, et al: Activating mutations in the epidermal growth factor receptor underlying responsiveness of non-small-cell lung cancer to gefitinib. N Engl J Med 350: 2129-2139, 2004

4. Zhu CQ, da Cunha Santos G, Ding K, et al: Role of KRAS and EGFR as biomarkers of response to erlotinib in National Cancer Institute of Canada Clinical Trials Group Study BR.21. J Clin Oncol 26: 4268-4275, 2008

5. Kosaka T, Yatabe Y, Endoh H, Kuwano H, Takahashi T and Mitsudomi T: Mutations of the epidermal growth factor receptor gene in lung cancer: biological and clinical implications. Cancer Res 64: 8919-8923, 2004.

6. Marchetti A, Martella C, Felicioni L, et al: EGFR mutations in non-small-cell lung cancer: analysis of a large series of cases and development of a rapid and sensitive method for diagnostic screening with potential implications on pharmacologic treatment. J Clin Oncol 23: 857-865, 2005.

7. Soung YH, Lee JW, Kim SY, et al: Mutational analysis of EGFR and K-RAS genes in lung adenocarcinomas. Virchows Arch 446: 483-488, 2005.

8. Sugio K, Uramoto $\mathrm{H}$, Ono K, et al: Mutations within the tyrosine kinase domain of EGFR gene specifically occur in lung adenocarcinoma patients with a low exposure of tobacco smoking. Br J Cancer 94: 896-903, 2006. 
9. Tomizawa Y, Iijima H, Sunaga N, et al: Clinicopathologic significance of the mutations of the epidermal growth factor receptor gene in patients with non-small cell lung cancer. Clin Cancer Res 11: 6816-6822, 2005.

10. Huang SF, Liu HP, Li LH, et al: High frequency of epidermal growth factor receptor mutations with complex patterns in nonsmall cell lung cancers related to gefitinib responsiveness in Taiwan. Clin Cancer Res 10: 8195-8203, 2004.

11. Shigematsu H and Gazdar AF: Somatic mutations of epidermal growth factor receptor signaling pathway in lung cancers. Int J Cancer 118: 257-262, 2006.

12. Wiwanitkit V: Squamous cell carcinoma of the lung: pattern of epidermal growth factor receptor mutation distribution in different populations: a summary. Lung 184: 301-302, 2006.

13. Sasaki H, Endo K, Mizuno K, et al: EGFR mutation status and prognosis for gefitinib treatment in Japanese lung cancer. Lung Cancer 51: 135-136, 2006.

14. Tatematsu A, Shimizu J, Murakami Y, et al: Epidermal growth factor receptor mutations in small cell lung cancer. Clin Cancer Res 14: 6092-6096, 2008

15. Janne PA, Borras AM, Kuang Y, et al: A rapid and sensitive enzymatic method for epidermal growth factor receptor mutation screening. Clin Cancer Res 12: 751-758, 2006.

16. Miyamae Y, Shimizu K, Mitani Y, et al: Mutation detection of epidermal growth factor receptor and KRAS genes using the smart amplification process version 2 from formalin-fixed, paraffin-embedded lung cancer tissue. J Mol Diagn 12: 257-264, 2010.

17. Araki T, Shimizu K, Nakamura K, et al: Usefulness of peptide nucleic acid (PNA)-clamp smart amplification process version 2 (SmartAmp2) for clinical diagnosis of KRAS codon 12 mutations in lung adenocarcinoma: comparison of PNA-clamp SmartAmp2 and PCR-related methods. J Mol Diagn 12: 118-124, 2010.

18. Mitani Y, Lezhava A, Kawai Y, et al: Rapid SNP diagnostics using asymmetric isothermal amplification and a new mismatchsuppression technology. Nat Methods 4: 257-262, 2007.

19. Cao W, Hashibe M, Rao JY, Morgenstern H and Zhang ZF: Comparison of methods for DNA extraction from paraffinembedded tissues and buccal cells. Cancer Detect Prev 27: 397-404, 2003

20. Tatsumi K, Mitani Y, Watanabe J, et al: Rapid screening assay for KRAS mutations by the modified smart amplification process. J Mol Diagn 10: 520-526, 2008.

21. Yu J, Kane S, Wu J, et al: Mutation-specific antibodies for the detection of EGFR mutations in non-small-cell lung cancer. Clin Cancer Res 15: 3023-3028, 2009

22. Brevet M, Arcila M and Ladanyi M: Assessment of EGFR mutation status in lung adenocarcinoma by immunohistochemistry using antibodies specific to the two major forms of mutant EGFR. J Mol Diagn 12: 169-176, 2010.

23. Kargi A, Gurel D and Tuna B: The diagnostic value of TTF-1, CK 5/6, and p63 immunostaining in classification of lung carcinomas. Appl Immunohistochem Mol Morphol 15: 415-420, 2007.

24. Khayyata S, Yun S, Pasha T, et al: Value of P63 and CK5/6 in distinguishing squamous cell carcinoma from adenocarcinoma in lung fine-needle aspiration specimens. Diagn Cytopathol 37: $178-183,2009$.

25. Kang SM, Kang HJ, Shin JH, et al: Identical epidermal growth factor receptor mutations in adenocarcinomatous and squamous cell carcinomatous components of adenosquamous carcinoma of the lung. Cancer 109: 581-587, 2007

26. Ohtsuka K, Ohnishi H, Fujiwara M, et al: Abnormalities of epidermal growth factor receptor in lung squamous-cell carcinomas, adenosquamous carcinomas, and large-cell carcinomas: tyrosine kinase domain mutations are not rare in tumors with an adenocarcinoma component. Cancer 109: 741-750, 2007.

27. Ricciardi S, Tomao S and de Marinis F: Toxicity of targeted therapy in non-small-cell lung cancer management. Clin Lung Cancer 10: 28-35, 2009.
28. Stinchcombe TE and Socinski MA: Current treatments for advanced stage non-small cell lung cancer. Proc Am Thorac Soc 6: 233-241, 2009

29. Chua YJ, Steer C and Yip D: Recent advances in management of small-cell lung cancer. Cancer Treat Rev 30: 521-543, 2004.

30. Sandler A and Herbst R: Combining targeted agents: blocking the epidermal growth factor and vascular endothelial growth factor pathways. Clin Cancer Res 12: 4421S-4425S, 2006.

31. Sandler A, Gray R, Perry MC, et al: Paclitaxel-carboplatin alone or with bevacizumab for non-small-cell lung cancer. N Engl J Med 355: 2542-2550, 2006.

32. Johnson DH, Fehrenbacher L, Novotny WF, et al: Randomized phase II trial comparing bevacizumab plus carboplatin and paclitaxel with carboplatin and paclitaxel alone in previously untreated locally advanced or metastatic non-small-cell lung cancer. J Clin Oncol 22: 2184-2191, 2004.

33. Scagliotti GV, Parikh P, von Pawel J, et al: Phase III study comparing cisplatin plus gemcitabine with cisplatin plus pemetrexed in chemotherapy-naive patients with advanced-stage nonsmall-cell lung cancer. J Clin Oncol 26: 3543-3551, 2008.

34. Hanna N, Shepherd FA, Fossella FV, et al: Randomized phase III trial of pemetrexed versus docetaxel in patients with nonsmall-cell lung cancer previously treated with chemotherapy. J Clin Oncol 22: 1589-1597, 2004.

35. Sasaki H, Endo K, Yukiue H, Kobayashi Y, Yano M and Fujii Y: Mutation of epidermal growth factor receptor gene in adenosquamous carcinoma of the lung. Lung Cancer 55: 129-130, 2007.

36. Mitsudomi T, Kosaka T, Endoh H, et al: Mutations of the epidermal growth factor receptor gene predict prolonged survival after gefitinib treatment in patients with non-small-cell lung cancer with postoperative recurrence. J Clin Oncol 23: 2513-2520, 2005.

37. Shigematsu H, Lin L, Takahashi T, et al: Clinical and biological features associated with epidermal growth factor receptor gene mutations in lung cancers. J Natl Cancer Inst 97: 339-346, 2005.

38. Takano T, Fukui T, Ohe Y, et al: EGFR mutations predict survival benefit from gefitinib in patients with advanced lung adenocarcinoma: a historical comparison of patients treated before and after gefitinib approval in Japan. J Clin Oncol 26: 5589-5595, 2008.

39. Park SH, Ha SY, Lee JI, et al: Epidermal growth factor receptor mutations and the clinical outcome in male smokers with squamous cell carcinoma of lung. J Korean Med Sci 24: 448-452, 2009.

40. Schreiber G and McCrory DC: Performance characteristics of different modalities for diagnosis of suspected lung cancer: summary of published evidence. Chest 123: 115S-128S, 2003.

41. Burnett RA, Howatson SR, Lang S, et al: Observer variability in histopathological reporting of non-small cell lung carcinoma on bronchial biopsy specimens. J Clin Pathol 49: 130-133, 1996.

42. Thomas JS, Lamb D, Ashcroft T, et al: How reliable is the diagnosis of lung cancer using small biopsy specimens? Report of a UKCCCR Lung Cancer Working Party. Thorax 48: 1135-1139, 1993

43. Vollmer RT, Ogden L and Crissman JD: Separation of smallcell from non-small-cell lung cancer. The Southeastern Cancer Study Group pathologists' experience. Arch Pathol Lab Med 108: 792-794, 1984

44. Inoue A, Kobayashi K, Usui K, et al: First-line gefitinib for patients with advanced non-small-cell lung cancer harboring epidermal growth factor receptor mutations without indication for chemotherapy. J Clin Oncol 27: 1394-1400, 2009.

45. Okami J, Taniguchi K, Higashiyama M, et al: Prognostic factors for gefitinib-treated postoperative recurrence in non-small cell lung cancer. Oncology 72: 234-242, 2007.

46. He C, Liu M, Zhou C, et al: Detection of epidermal growth factor receptor mutations in plasma by mutant-enriched PCR assay for prediction of the response to gefitinib in patients with non-small-cell lung cancer. Int J Cancer 125: 2393-2399, 2009. 